\title{
FOREWORD
}

\section{First Words}

\section{Jacob Palis}

$\mathbf{F}$ OR at least the past two centuries, the application of scientific and technological knowledge has been a critical factor in human development. Such knowledge proved instrumental in launching the industrial revolution in the eighteenth century, transforming transportation systems in the nineteenth century, protecting many countries from famine in the twentieth century and spurring the rapid advance of electronic information in the twentyfirst century.

Today, more than ever, public and policymakers are looking to the community of scientific researchers to play a fundamental role in addressing present and future problems. However, this time, the problems we are facing - global warming, food and energy insecurity, and loss of biodiversity, to name the most prominent among them - are more numerous, more urgent, more complex and therefore more difficult to solve.

Solutions will require the collective insights and experience of scientists, policy-makers, industry and non-governmental groups.

A World of Science in the Developing World, a TWAS Supplement to the Nature Publishing Group, is being produced on the occasion of the twenty-fifth anniversary of TWAS, the academy of sciences for the developing world. The academy, which is administered by the United Nations Educational, Scientific and Cultural Organization (UNESCO) and generously supported by the Italian government, is dedicated to supporting the development and application of science and technology (S\&T) in developing countries.

Despite enormous disparities in S\&T capabilities between nations, the world has come a long way from the notion that prevailed at the time of the founding of TWAS, when it was common

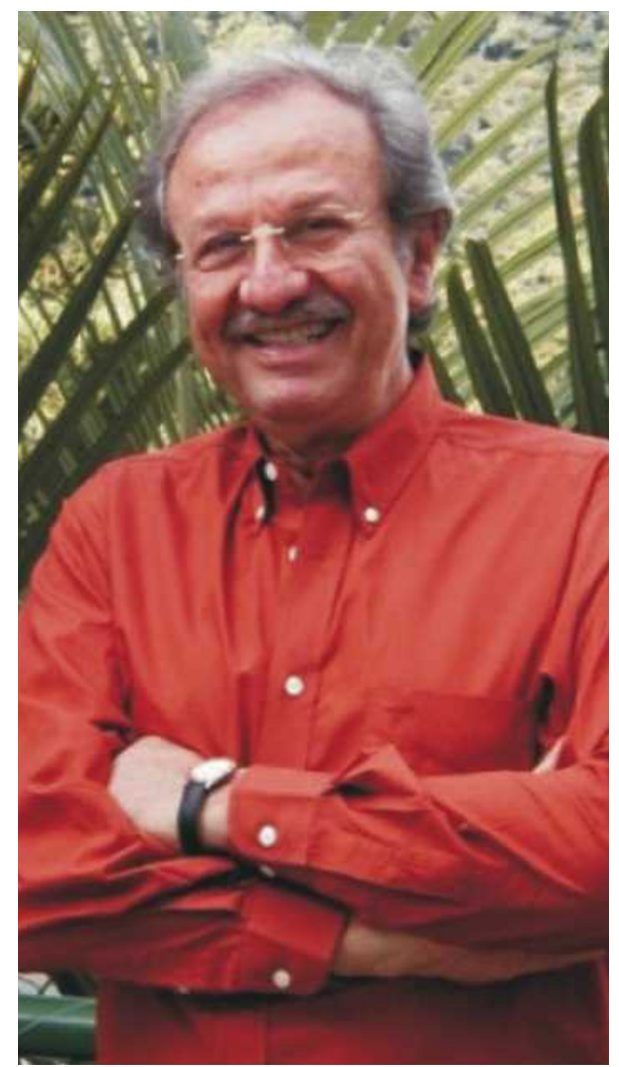

period of global transition, marked by unprecedented growth in S\&T and rapidly expanding S\&T capacity in significant portions of the South. Yet, this is also a time of increasing disparities in S\&T capacity, both within and between countries - disparities that have direct implications for economic and social well-being. One consequence is that countries left behind in the quest for science-based development have become more marginalized than ever.

The academy has always been convinced that the application of knowledge is an indispensable force for economic development, social justice and a better understanding among the peoples of our world. It has been the guiding purpose of TWAS to be both an active participant and a keen observer of science and science-based development in the developing world. This effort has borne much fruit, yet much more remains to be done.

A World of Science in the Developing World is a reflection of the insights and expertise of TWAS members and scientists who have been closely associated with the academy. It is my firm belief that the academy's quarter century of activity in promoting S\&T capacity in the developing world will remain a great source of inspiration and strength in the years ahead, as we seek to navigate successfully the opportunities and challenges that are influencing the world in which we live - a world of unprecedented change for

to hear economic-development experts and policy-makers say that investing in scientific and other forms of knowledge was a luxury that only rich nations could afford. Indeed, TWAS itself was created, in part, in response to this misguided view.

A World of Science in the Developing World takes stock of the state of S\&T during a critical both science and society. .
Jacob Palis is president of TWAS, the academy of sciences for the developing world, in Trieste, Italy. $\mathrm{He}$ also serves as president of the Brazilian Academy of Sciences in Rio de Janeiro, Brazil.

\section{From Philip Campbell, editor-in-chief of Nature publications}

Nature Publishing Group (NPG) is delighted to be collaborating with TWAS, the academy of sciences for the developing world, in the publication of $A$ World of Science in the Developing World. This supplement to the NPG, which coincides with the $25^{\text {th }}$ anniversary of TWAS, is designed to explore the state of science in the developing world.

At Nature, we regularly cover science and technology in the Southern hemisphere and many of the authors in this publication have written for - or have been featured in - NPG journals. We therefore welcome this addition to the growing literature on science and technology in the developing world. A World of Science in the Developing World, however, is an independent publication and the opinions expressed in the pages that follow are strictly those of the authors and not of Nature or the NPG.

The supplement will be distributed free of charge upon request. It can also be browsed and downloaded at www.nature.com/twas/. We sincerely hope that you take time to examine this broad-ranging survey of science and science-based development in the South. If readers would like additional copies of $A$ World of Science in the Developing World, please contact: feedback@nature.com. 